\title{
Salmonella em ovos: relação entre produção e consumo seguro
}

\author{
Giovana Verginia Barancelli ${ }^{1}$, José Guilherme Prado Martin ${ }^{2}$, Ernani Porto ${ }^{2}$
}

Salmonella é um dos principais patógenos envolvidos em casos e surtos de Doenças Transmitidas por Alimentos (DTAs). Entre os principais veículos do patógeno estão os ovos e alimentos à base de ovos crus ou mal cozidos. A complexa epidemiologia de Salmonella dificulta seu controle no ambiente de produção avícola e representa uma constante preocupação em termos de segurança alimentar, tanto na produção quanto no processamento e consumo de ovos. Além de programas de Boas Práticas de Fabricação e Análise de Perigos e Pontos Críticos de Controle - APPCC na indústria, é fundamental o papel de manipuladores e consumidores na diminuição dos riscos de salmoneloses, principalmente em relação a contaminações cruzadas. Por maiores que sejam os esforços, não é possível garantir a inocuidade de um produto in natura como o ovo; é imprescindível, portanto, a execução de ações educativas sobre práticas seguras de compra, armazenamento e manipulação de ovos. Tendo em vista a importância epidemiológica de Salmonella para as DTAs e a problemática de sua ocorrência na cadeia de produção avícola e em ovos, a presente revisão tem por objetivo discutir, no âmbito da Segurança Alimentar e Nutricional, a relação entre produção e consumo seguro de ovos, identificando as principais medidas para se garantir sua segurança biológica e sanitária.

Palavras-chave: ovos, Salmonella, contaminação, produção.

\section{Salmonella in eggs: relation between production and safe consumption}

Salmonella is one of the main pathogens related to foodborne diseases and outbreaks. Eggs and food based with raw or undercooked eggs are among the principal pathogen transmitters. Complex Salmonella epidemiology hampers its control in poultry production environment and represents a constant concern in terms of food safety, both in production, as processing and eggs consumption steps. Besides Good Manufacturing Practices and Hazard Analysis and Critical Control Point - HACCP programs in industries, the role of producers and consumers in decreasing the risk of salmonellosis is fundamental, mainly in relation to cross contamination. Even though after big efforts, it is not possible to guarantee innocuousness in in natura products such as eggs. So, it is indispensable to carry out educational actions about safe practices in buying, storing and manipulating eggs. Considering the Salmonella epidemiological relevance for foodborne diseases and the problematics of its occurrence in the eggs and poultry production chain, this review has the aim to discuss, in the context of the Food and Nutrition Security, the relation between production and safe consumption of eggs, pointing out the main actions to assure its biological and sanitary safety.

Key-words: eggs, Salmonella, contamination, production.

\footnotetext{
${ }^{1}$ Departamento de Agroindústria, Alimentos e Nutrição (LAN), Escola Superior de Agricultura “Luiz de Queiroz" (ESALQ), Universidade de São Paulo (USP). Av. Pádua Dias, 11, CEP 13418-900, Piracicaba, SP. Tel. (19) 9654-8969.E-mail: giovana.rangel@terra.com.br.

${ }^{2}$ Departamento de Agroindústria, Alimentos e Nutrição (LAN), ESALQ/USP.
} 


\section{INTRODUÇÃO}

Salmonella é o principal agente causador de doenças de origem alimentar em várias partes do mundo, inclusive no Brasil. Carne de frango, ovos e alimentos à base de ovos estão entre os principais veículos do patógeno para humanos [1,2]. Na produção avícola, Salmonella representa uma ameaça, tanto pelo risco da transmissão vertical de alguns sorotipos para novas gerações de aves quanto pela contaminação da carne de frango e de ovos de consumo. A epidemiologia do gênero Salmonella é complexa, o que dificulta seu controle na produção avícola industrial; consiste, assim, em motivo de preocupação nesse meio e, por conseguinte, na indústria de alimentos, em termos de segurança alimentar.

Atualmente há mais de 2.500 sorotipos de Salmonella identificados [3], com cerca de 200 isolados de aves. A sorotipagem é importante do ponto de vista epidemiológico, pois permite rastrear contaminações e estabelecer o padrão de distribuição de Salmonella na cadeia de alimentos, auxiliando nos programas de prevenção e controle do patógeno [4]. Para fins epidemiológicos, as salmonelas podem ser divididas, com base na especificidade do hospedeiro e no padrão clínico por elas determinados, em três categorias: salmonelas altamente adaptadas ao homem (causadoras das febres tifóide e paratifóide) - representadas por $S$. Typhi e $S$. Paratyphi; salmonelas altamente adaptadas aos animais - representadas por $S$. Dublin (bovinos), $S$. Choleraesuis (suínos), S. Pullorum e $S$. Gallinarum (aves), dentre outras; e, por fim, salmonelas não adaptadas a hospedeiros, que incluem a maioria dos sorotipos e atingem indiferentemente homens e animais, sendo responsáveis pelas chamadas salmoneloses [5], com destaque para $S$. Typhimurium e $S$. Enteritidis.

Nos EUA, estima-se a ocorrência anual de 142.000 casos de salmoneloses devido ao consumo de ovos contaminados com Salmonella [6], representando um importante problema de saúde pública. Em termos de segurança alimentar, a problemática da presença do patógeno em ovos relaciona-se diretamente ao conceito de food safety; a qualidade sanitária de ovos e produtos de ovos deve ser assegurada de modo que sua ingestão não cause prejuízos à integridade física de consumidores. O número real de casos, entretanto, pode ser superior, uma vez que a identificação do agente etiológico nem sempre é possível [1]. No Brasil, $42,5 \%$ dos surtos alimentares confirmados laboratorialmente de 1999 a 2009 tiveram como agente etiológico bactérias do gênero Salmonella [2], frequência muito provavelmente subestimada.

A salmonelose é uma infecção cujos sintomas são febre, dores abdominais, vômito e diarreia, e se manifestam de 12 a 36 horas após o consumo de alimentos ou bebidas contaminados, com duração de 1 a 4 dias. A recuperação ocorre geralmente sem o uso de antibióticos. Em crianças, recém-nascidos e indivíduos imunocomprometidos, a Salmonella pode provocar danos mais graves, como bacteremia, lesões em órgãos e meningites; nesses casos, a antibioticoterapia é imprescindível. Diversos fatores podem afetar a dose infectante de Salmonella, como sorotipo, condição imunológica do indivíduo e tipo de alimento envolvido [7].

Em meados da década de 1980, aumentou a frequência de Salmonella Enteritidis (SE) como agente etiológico de salmoneloses em países da Europa, América do Norte e do Sul, relacionadas principalmente ao consumo de carne de aves e ovos crus ou insuficientemente cozidos [8]. No Brasil, esse sorotipo emergiu como grande problema de saúde pública a partir da década de 1990, quando surgiram os primeiros relatos de toxinfecção causada pelo consumo de produtos avícolas [?]. Desde então, ovos têm sido a fonte mais comum de infecções humanas por SE [2,10].

Esse sorotipo apresenta propriedades intrínsecas que lhe permitem uma interação particular com o trato reprodutor de aves e alguns componentes do ovo [10]. Por não possuir um hospedeiro específico, a infecção de galinhas por SE geralmente é silenciosa, sem sinais de morbidade e mortalidade. Dessa maneira, pode permanecer no ambiente de produção avícola sem que seja possível observar qualquer indicação externa de infeção das aves ou contaminação dos ovos por elas produzidos [11].

Uma estimativa da magnitude do impacto de SE sobre a indústria de alimentos pode ser obtida analisando sua ocorrência em ovos destinados à comercialização. Nos Estados Unidos, na década de 1990, para cada 20.000 ovos produzidos, a estimativa era de que 1 apresentava contaminação interna por SE [12]. Esse número pode parecer insignificante, mas diante dos 65 bilhões de ovos produzidos ao ano, o número de unidades contaminadas poderia chegar a 2,2 milhões, representando um grande número de pessoas expostas a tais produtos [13]. 
O Brasil produziu, nos dois primeiros trimestres de 2012, aproximadamente 16 bilhões de unidades de ovos [14]. No país, são escassos os levantamentos sobre a presença de Salmonella em ovos comerciais e aves de postura, existindo diferenças regionais de prevalência. No Estado de São Paulo, uma pesquisa detectou contaminação por SE no conteúdo $(3,2 \%)$ e na casca $(9,6 \%)$ de ovos de consumo [15]; em outra região do Estado, entretanto, Salmonella não foi isolada em nenhuma das amostras analisadas $(n=60)$ provenientes de fornecedores distintos [16]. Em diversos países da União Europeia, a prevalência de Salmonella em ovos de mesa varia entre zero a $22,6 \%$, com média de 0,4 [17]; a contaminação de cascas pode atingir índices de $0,04 \%$ a $9,0 \%$ [18]. Nos Estados Unidos, pesquisas revelam a ocorrência do patógeno na superfície de ovos em 0,8 a 1,1\% das amostras analisadas ${ }^{[18]}$.

Tendo em vista a importância epidemiológica de Salmonella para as doenças transmitidas por alimentos, sua frequente ocorrência na cadeia de produção avícola e em ovos, a presente revisão tem por objetivo estabelecer, da granja à mesa do consumidor, os principais pontos de contaminação e de controle do patógeno. As ações de prevenção de Salmonella em ovos apontadas nesse artigo inserem-se no âmbito da Segurança Alimentar e Nutricional, mais especificamente no tocante aos aspectos do food safety, à medida que visam à produção de alimentos inócuos, a fim de se garantir a qualidade biológica e sanitária de ovos.

\section{Salmonella NA GRANJA}

Os sorotipos especificamente adaptados às aves - $S$. Pullorum e $S$. Gallinarum - que podem causar doença e morte de galinhas e perus estão praticamente erradicados da avicultura de corte no Brasil, aparecendo com maior frequência em aves caipiras e eventualmente em aves de postura comercial. Outros sorotipos, como SE, despertam grande preocupação no momento, devido à sua importância em saúde pública e ao fato de serem encontrados facilmente no ambiente de criação avícola, sem causar morbidade ou mortalidade das aves [4].

A infecção de aves por Salmonella ocorre pela ingestão da bactéria, que pode colonizar o intestino. Macrófagos produzidos fagocitam o patógeno; infectados, os macrófagos podem migrar para órgãos internos da ave e contaminar o trato reprodutor (ovários e oviduto). S. Enteritidis apresenta propriedades intrínsecas que lhe permitem uma interação particular com esses órgãos reprodutores. Outra possibilidade de contaminação dessas estruturas é via ascendente, através da cloaca [10]. Em termos de disseminação de Salmonella no ambiente avícola, atentase para o fato da principal fonte ser constituída pelo trato digestório, incluindo o ceco, de onde a bactéria pode ser excretada pelas fezes e servir de fonte de disseminação do patógeno [5].

Uma vez infectadas, as aves eliminam Salmonella de forma intermitente e em número baixo, o que dificulta o monitoramento de contaminações [4]. No caso de SE, sua habilidade em persistir em ambientes de produção, infectar assintomaticamente ovários de galinhas e contaminar ovos internamente permitiu sua ampla disseminação no sistema de produção avícola [1]. Pintainhas destinadas à postura comercial expostas à SE logo após o nascimento podem permanecer infectadas até a maturidade e, a qualquer momento, produzir ovos contaminados ou disseminar a bactéria para outras aves [19].

A entrada de Salmonella no ambiente da granja pode ocorrer de várias maneiras, como pelo contato das aves com insetos, roedores e pássaros silvestres portadores. Outras fontes de contaminação são utensílios e ração contaminados e o próprio homem, além da água. Assim, o ambiente criatório tem papel fundamental na epidemiologia de Salmonella na criação avícola. Matéria orgânica e umidade constituem nichos onde diversos sorotipos podem sobreviver e se multiplicar por períodos prolongados. A alta densidade de aves nos sistemas atuais de produção favorece a disseminação da bactéria pelo contato direto com aves infectadas e com o ambiente contaminado ${ }^{[1]}$.

Rações comerciais também são potenciais veículos de transmissão de Salmonella. Ingredientes de origem animal ou vegetal contaminados representam um perigo microbiológico, bem como o ambiente de processamento, transporte e armazenamento [20]. Tratamentos térmicos e químicos da ração são alternativas eficientes de controle da contaminação; peletização a $80{ }^{\circ} \mathrm{C}$ é uma medida eficaz de descontaminação [21], embora na prática grande parte da ração de poedeiras no Brasil seja na forma farelada. A importância do monitoramento contínuo na produção da ração, dentro do programa de Análise de Perigos e Pontos Críticos de Controle - APPCC, e a adoção de ações corretivas na detecção da contaminação são fundamentais para prevenir a introdução da Salmonella 
na produção animal e subsequentemente na cadeia de alimentos [20].

Diversas regiões dos EUA apresentam contaminação por SE em poedeiras [13]. Na União Europeia, pesquisa com mais de 5 mil granjas de postura mostrou que $31 \%$ eram positivas para Salmonella no ambiente, com predomínio de SE [22]. No Brasil, dados de prevalência de Salmonella em granjas de postura são escassos. O patógeno foi detectado em forros de caixas de transporte de pintos recém-nascidos destinados a granjas de postura e corte, sugerindo que a transmissão vertical do agente constitui uma importante via de introdução de Salmonella em granjas de postura [23].

Toda a complexidade da epidemiologia de Salmonella torna difícil seu controle no ambiente de produção. Produtores devem garantir a qualidade dos seus produtos e trabalhar no sentido de minimizar os riscos de contaminação de aves e ovos. O controle de Salmonella exige a adoção de diversas medidas de biosseguridade; ferramentas de controle eficientes consistem nas Boas Práticas de Produção na Granja e na adoção do Programa de Prevenção de Salmonella, com destaque para SE.

O primeiro passo para prevenir sua introdução em granjas é evitar a transmissão vertical, com medidas de prevenção para redução da contaminação de pintos de um dia ou ovos destinados à incubação. Medidas de redução da transmissão horizontal de Salmonella também são imprescindíveis. A aplicação de programas de vacinação contra Salmonella em matrizes auxiliaria no controle de sua ocorrência em granjas, evitando-se, assim, a contaminação da progênie. No entanto, essa medida pode ser de difícil aplicação, uma vez que as vacinas não são polivalentes e não permitem imunidade cruzada entre os diversos sorotipos [4].

No caso de SE, entre os métodos disponíveis para controle identifica-se a vacinação de matrizes e poedeiras com vacinas inativadas; seu uso, contudo, deve ser complementar às práticas de manejo e de higienizações. A vacinação de galinhas para prevenção da transmissão de Salmonella pode representar uma medida de proteção de consumidores de ovos. Entretanto, há divergências em relação à sua eficácia para tal finalidade [24].

O desenvolvimento de programas de garantia da qualidade em granjas é uma estratégia para solucionar o problema da presença de SE. Planos abrangentes para limitar a contaminação no ambiente agrícola incluem a higienização de ovos destinados à incubação, o uso de exclusão competitiva, cloração da água $(0,2 \mathrm{mg} / \mathrm{L}$ de cloro residual livre), aquisição de pintos certificados como livres da bactéria, controle de pragas, restrição de acesso e movimento de pessoal e equipamentos entre aviários, uso adequado de rações, higienização das instalações entre lotes e rotina de monitoramento de SE no ambiente [1,25].

\section{CONTAMINAÇÃO E COMPORTAMENTO DE Salmonella EM OVOS}

Apesar da alta incidência de $S$. Enteritidis em lotes de aves de postura, a ocorrência de ovos contaminados é considerada baixa [12]. A contaminação de ovos pode ocorrer de duas maneiras: internamente, durante sua formação, a partir do trato reprodutor infectado (contaminação vertical) ou pela penetração da bactéria através da casca (contaminação horizontal), contaminada pela passagem pela cloaca ou pelo contato com material fecal do ambiente e, eventualmente, com o sistema reprodutor após sua formação [10]. Qualquer sorotipo de Salmonella pode contaminar a casca e, a partir daí, o interior do ovo. A contaminação transovariana do ovo, durante a formação, é especialmente importante para $S$. Enteritidis, além dos sorotipos adaptados às aves, $S$. Gallinarum e $S$. Pullorum [1,26].

A estrutura do ovo apresenta barreiras físicas e químicas contra a contaminação por patógenos, tais como casca e membranas e componentes antimicrobianos [25]. A casca de um ovo contém milhares de poros e é revestida externamente por uma fina cutícula protéica, que a torna impermeável, e internamente por duas membranas subjacentes, as quais lhe fornecem resistência adicional à penetração por micro-organismos [10]. A função dos poros é permitir trocas gasosas através da casca. Logo após a postura, a evaporação de água reduz o volume dos conteúdos e forma-se uma câmara de ar entre as membranas interna e externa [25].

Cascas com peso específico elevado, com menos poros, apresentam maior resistência à penetração bacteriana, inclusive Salmonella. A espessura da casca tende a diminuir com a idade da ave e varia com sua dieta. Quanto à cutícula, esta pode ser danificada pela limpeza dos ovos com substâncias 
abrasivas, o que aumenta as chances de invasão de micro-organismos [25]. S. Enteritidis é incapaz de penetrar em ovos de casca íntegra, a menos que seja "forçada" para seu interior por fatores como remoção da cutícula (por lavagem inadequada), penetração de água através dos poros por capilaridade e, principalmente, pelo surgimento de pressão negativa [27].

Tal fenômeno está relacionado com a contração da câmara de ar existente entre as membranas do ovo, que ocorre com a diminuição da temperatura. Em cascas sujas e úmidas, à medida que a diferença de pressão se equilibra através da casca, água e bactérias contaminantes são aspiradas para o interior do ovo, permanecendo retidas na superfície de sua membrana interna. Esse fenômeno é mais pronunciado à medida que o ovo envelhece e a câmara de ar aumenta de volume [25].

A persistência de Salmonella na casca de ovos experimentalmente contaminados pode chegar a 21 dias, tanto para os mantidos em temperatura ambiente quanto para os mantidos sob refrigeração [15], embora estudos recentes demonstrem maior sobrevivência de Salmonella na casca de ovos armazenados a $8^{\circ} \mathrm{C}$ do que a $30^{\circ} \mathrm{C}$. Entretanto, em temperatura ambiente, ocorre um aumento na tendência de penetração da bactéria nos ovos [28]. Ademais, a viabilidade de SE parece diminuir na superfície de ovos mantidos à temperatura de $30{ }^{\circ} \mathrm{C}$, independentemente da qualidade da casca, com uma maior tendência de penetração da bactéria em ovos com casca defeituosa se expostos a essa temperatura [29].

A prevalência de ovos contaminados por SE na casca varia amplamente dentre lotes infectados [25]. Ainda não está elucidado se é a contaminação fecal ou transovariana do ovo a principal causa de infecções em humanos [10]. Entretanto, as salmoneloses ligadas ao consumo de ovos são atribuídas principalmente a ovos contaminados verticalmente, de casca limpa e aparência normal [13]. Cabe ressaltar que contaminações cruzadas em cozinhas podem conferir riscos de salmonelose maiores do que o consumo de ovos crus ou mal cozidos, representando um fator importante para a disseminação de Salmonella e que deve ser rigorosamente controlado [18].

Uma vez ultrapassadas as barreiras externas, os micro-organismos encontram, no interior do ovo, um ambiente desfavorável tanto para sua sobrevivência quanto para sua multiplicação - o albúmen, popularmente conhecido como clara, é rico em antimicrobianos e carece de ferro disponível para o desenvolvimento bacteriano. O fato de se encontrar SE no interior de ovos é atríbuído à adaptação e resistência de algumas linhagens [10].

Durante a formação dos ovos, a estrutura a ser contaminada por SE depende da região de infecção do trato reprodutivo das aves. Geralmente, a contaminação ocorre no albúmen. A sobrevivência da bactéria nessa estrutura é influenciada pelo tempo transcorrido a partir da postura dos ovos. Ovos de galinha recém-postos têm valores de $\mathrm{pH}$ entre 7,6-7,8. A perda de $\mathrm{CO}_{2}$ do ovo para a atmosfera faz com que o pH do albúmen aumente para 9,1-9,6 após 1 a 3 dias de armazenamento à temperatura ambiente, tornando o ambiente desfavorável para o desenvolvimento do patógeno [30].

A contaminação da gema ocorre principalmente pela associação do micro-organismo à membrana vitelina do ovo [30]. Seu rompimento, durante o armazenamento dos ovos, permite a migração do patógeno para a gema, estrutura que oferece condições nutricionais e ambiente favorável para o desenvolvimento de SE. Cabe salientar que um dos fatores que favorecem o rompimento da membrana vitelina são condições de temperaturas de abuso [31].

A temperatura de acondicionamento de ovos contaminados por Salmonella está diretamente relacionada ao risco de salmoneloses, pois influencia no número de bactérias contaminantes ${ }^{[10]}$. $\mathrm{Na}$ gema, um baixo número de células viáveis pode se multiplicar e atingir concentrações perigosas em apenas 24 horas. Multiplicação rápida tem sido relatada em temperaturas superiores a $15{ }^{\circ} \mathrm{C}$, enquanto que a $10{ }^{\circ} \mathrm{C}$ ocorre mais vagarosamente, cessando a $4{ }^{\circ} \mathrm{C}$ [32]. Em geral, as alterações físico-químicas causadoras de perda da qualidade do ovo sofrem influência principalmente da temperatura; logo, o resfriamento rápido do produto torna-se imprescindível [33].

\section{OVOS versus Salmonella: TRANSPORTE, ARMAZENAMENTO, PROCESSAMENTO E PRÁTICAS PARA O CONSUMO SEGURO}

Os principais fatores que fazem do ovo um potencial causador de salmoneloses são hábitos 
inadequados de preparo e consumo - cru ou mal cozido, principalmente em pratos à base de ovos sem cocção. Um único ovo com $\mathrm{SE}$ pode contaminar grandes quantidades de alimentos e expor um elevado número de consumidores ao patógeno [1]. Contaminações cruzadas podem introduzir Salmonella em outros alimentos, inclusive alimentos que não contenham ovos, fato especialmente importante para os alimentos prontos para consumo.

Medidas gerais de prevenção de contaminação cruzada devem ser rigorosamente cumpridas quando se manipula alimentos in natura como ovos e outros produtos de origem animal crus, o que também é válido para vegetais não higienizados. A higienização correta das mãos, durante e após a manipulação desses alimentos, é uma medida simples, mas imprescindível. Utensílios utilizados para manipulação de ovos in natura também devem ser higienizados.

Nas granjas, após o recolhimento e classificação, os ovos podem ser embalados e enviados diretamente para a comercialização, ou encaminhados para um entreposto, onde são embalados. Recomendase a refrigeração em todas as fases de processamento na cadeia produtiva de ovos, mas no Brasil não há exigência nem fiscalização para controle deste procedimento [29]. Algumas granjas lavam os ovos, outras não. A prática de limpeza a seco também elimina a cutícula dos ovos, tornando-os mais sensíveis à penetração microbiana e a alterações, no caso de umedecerem-se posteriormente [25].

A lavagem pode melhorar a qualidade microbiológica das cascas, porém deve ser rigorosamente controlada, com monitoramento da qualidade microbiológica da água e temperatura adequada [34], que deve estar entre 35 e $45^{\circ} \mathrm{C}$, ou ao menos $10{ }^{\circ} \mathrm{C}$ acima da temperatura dos ovos [35]. Temperaturas inferiores às dos ovos podem produzir um gradiente de pressão e facilitar a entrada de água e de micro-organismos [10]. Ovos não devem ser armazenados úmidos; portanto, é fundamental executar a secagem imediata após a lavagem, além do controle de recontaminações do produto após a lavagem.

No Brasil, os ovos são transportados das granjas para entrepostos ou distribuídos para o comércio em caminhões-baú, sem controle de temperatura; chegam aos pontos de venda à temperatura ambiente, permanecendo nessa condição durante todo o período de comercialização [36. A falta de controle de tempo entre a produção e o consumo é um ponto crítico dessa cadeia produtiva, uma vez que no rótulo das embalagens de ovos consta apenas a data de embalagem e não a da postura.

Estudos indicam que o armazenamento de ovos em temperaturas baixas e constantes é eficaz no controle de Salmonella. A oscilação de temperatura durante o armazenamento favorece a sobrevivência do patógeno na casca e sua penetração no interior do ovo. S. Enteritidis é capaz de se multiplicar em albúmen armazenado a $30{ }^{\circ} \mathrm{C}$ independentemente dos agentes antimicrobianos presentes, enquanto que a $8{ }^{\circ} \mathrm{C}$ o patógeno tende a ser inviabilizado [37].

A manutenção de ovos sob refrigeração previne que Salmonella eventualmente contaminante se multiplique e atinja altas populações; portanto, ovos devem ser refrigerados até sua utilização [13]. Temperaturas de armazenamento inferiores a $8{ }^{\circ} \mathrm{C}$ retardam o crescimento de bactérias e mantêm a qualidade interna do ovo. Em temperaturas de até 18 ${ }^{\circ} \mathrm{C}$, suas barreiras naturais se deterioram lentamente, enquanto que acima de $18{ }^{\circ} \mathrm{C}$ ocorre acelerada degradação. À medida que diminui a eficácia dessas barreiras, o ovo torna-se cada vez mais vulnerável à penetração e ao crescimento microbiano [25].

A penetração de salmonelas e bactérias det eriorantes no ovo aumenta quanto maior for o tempo de contato com o material contaminado, especialmente durante o armazenamento em elevadas Umidades Relativas (UR). Para armazenamento de ovos, recomenda-se UR entre 70 e $85 \%$ [25]. Abaixo de 70\%, ocorre perda rápida de peso específico por evaporação, que interfere negativamente na qualidade do ovo, enquanto acima de $85 \%$ aumenta a penetração microbiana. Oscilações na temperatura podem ocasionar condensação de umidade na superfície externa do ovo, favorecendo a penetração de Salmonella [29].

Para produtores, a legislação brasileira recomenda, para curtos períodos - máximo de 30 dias, armazenamento em temperaturas entre 4 a $12{ }^{\circ} \mathrm{C}$, com controle da UR. Para períodos mais longos, recomenda-se a utilização de temperaturas em torno de $0{ }^{\circ} \mathrm{C}$, com UR entre 70 e $80 \%$ [35]. Para consumidores domésticos, é recomendado o acondicionamento dos ovos em caixas plásticas com tampa, devendo ser retirados da embalagem original, mantidos nas prateleiras da geladeira, e não na porta, para evitar 
flutuações de temperatura [38], e armazenados sempre com a extremidade alargada voltada para cima, onde se localiza a câmara de ar [25]. Outras recomendações incluem: adquirir ovos limpos e de casca íntegra; conferir o prazo de validade; verificar, no momento da compra, se o local de armazenamento é arejado, limpo e fresco, longe de fontes de calor e de preferência refrigerado; não misturar a casca com o conteúdo do ovo no momento do uso e não reutilizar embalagens de ovos [39]. Não é recomendada a lavagem de ovos para consumo doméstico antes de serem armazenados.

Salmonella é destruída com cozimento adequado; recomenda-se gema e clara duras e, no caso de preparações mistas, a temperatura no centro geométrico do alimento deve atingir $74{ }^{\circ} \mathrm{C}$. Ovos inteiros não necessitam de higienização, tendo em vista que devem ser consumidos após cocção atingindo 74 ${ }^{\circ} \mathrm{C}$ no interior ${ }^{[40]}$.

Uma pesquisa sobre práticas adotadas na compra e utilização de ovos por consumidores no Estado de São Paulo identificou como fator de risco o consumo de ovos fritos com gema mole, suflês, musses e coberturas para bolo com ovos crus. Os entrevistados que conheciam a existência de risco de contaminação por práticas inadequadas relataram consumir menos preparações com ovos crus e mal cozidos, quando comparados com os outros participantes [41].

Preparo e manipulação inadequada em residências e estabelecimentos de alimentação são as principais causas de surtos e casos de salmoneloses [5]. Surtos por SE associados ao consumo de ovos geralmente envolvem ocorrência de temperaturas de armazenamento inadequadas, ocorrência de contaminações cruzadas em cozinhas e serviços de alimentação e métodos inadequados de cocção [42], o que demonstra a necessidade de informação e orientações para manipuladores de alimentos e consumidores.

Com base na frequente associação entre salmonelose e consumo de ovos, a Agência Nacional de Vigilância Sanitária - ANVISA determinou que produtores estampem nas embalagens de ovos as seguintes descrições: "O consumo deste alimento cru ou mal cozido pode causar danos à saúde" e "manter os ovos preferencialmente refrigerados" [43]. Para estabelecimentos comerciais, a legislação proíbe a comercialização de pratos nos quais ovos permaneçam crus [40]. Para atender a tal parâmetro, pode-se optar pelo preparo de pratos em que ovos sejam completamente cozidos ou a utilização de ovos processados, obtidos a partir de ovo integral, clara ou gema, retiradas suas cascas e membranas. Ovos processados são seguros com relação à Salmonella, pois passam pelo processo de pasteurização.

Esse processo compreende um dos pontos críticos na fabricação de ovos processados e sua execução deve ser controlada de modo a não modificar as propriedades funcionais do ovo e garantir a destruição de patógenos contaminantes. Após a quebra dos ovos, deve-se proceder a pasteurização dentro de 72 horas, desde que mantidos sob refrigeração (2 a 5 $\left.{ }^{\circ} \mathrm{C}\right)$, para impedir a deterioração do produto. A temperatura de pasteurização pode variar de 55,5 a 63,5 ${ }^{\circ} \mathrm{C}$, dependendo do tipo de conserva de ovos a ser produzido, o que também determina o tempo de pasteurização, que pode variar de 3,5 a 6,2 minutos [35].

No mercado brasileiro, a maioria dos ovos comercializados é adquirida em hipermercados, supermercados, mercearias, feiras e vendedores ambulantes [41], na forma in natura. Produtos de ovos também constituem parte importante do comércio e o processamento é uma alternativa para prolongar suas condições de consumo, agregando valor em relação ao produto fresco, além de manter suas características químicas relativamente inalteradas e torná-lo mais seguro. Vários produtos obtidos a partir do processamento do ovo in natura têm ganhado destaque no mercado nacional, como ovos pasteurizados refrigerados, congelados e em pó, constituídos de ovo integral ou clara e gema, separadamente [44].

$\mathrm{Na}$ indústria de alimentos, há preferência pelo uso de ovos processados, pois além de apresentarem atributos de sabor, cor, valor nutritivo e propriedades funcionais comparáveis aos do ovo in natura, possuem diversas vantagens operacionais, como maior durabilidade, melhora na logística para distribuição e armazenamento e maior segurança microbiológica quanto à contaminação por Salmonella e outras bactérias patogênicas. Além disso, suas características de viscosidade, emulsificação, geleificação e formação de espumas, importantes para a indústria de alimentos, melhoram a qualidade do produto final [44].

Ressalta-se a importância de se assegurar o controle de Salmonella em alimentos prontos para o consumo, uma vez que um número baixo de células viáveis pode causar salmonelose. Além de cocção 
adequada de ovos e alimentos à base de ovos, é importante que se evitem contaminações cruzadas, respeitando-se as condições de tempo e temperatura [40] nas etapas de pós-preparo e distribuição.

\section{CONSIDERAÇÕES FINAIS}

O ovo é um dos alimentos mais nutritivos da natureza, fonte de proteínas de alto valor biológico e de baixo custo. No entanto, dados epidemiológicos demonstram sua importância como veículo de Salmonella para a população em todo o mundo. Por estar distribuída amplamente no ambiente e na população animal, é pouco realista esperar a total eliminação de Salmonella em animais de produção, especialmente aves. Portanto, a prevenção de salmoneloses decorrentes do consumo de ovos é de responsabilidade de toda a cadeia de produção e comercialização, de modo a se minimizarem os riscos de contaminações por Salmonella no produto final. Produtores têm a responsabilidade de fornecer alimentos seguros e implementar programas de controle do patógeno. Contudo, por maiores que sejam os esforços, não é possível garantir a inocuidade de um produto in natura como o ovo; é imprescindível, pois, o papel desempenhado por manipuladores de alimentos e consumidores finais nas práticas preventivas, sendo fundamental o desenvolvimento de ações educativas sobre práticas seguras de compra, armazenamento, manipulação e preparo de ovos para esse público específico. Nesse contexto, as unidades de alimentação ficam responsáveis pelo treinamento de funcionários para a produção de alimentos livres de Salmonella. Aos órgãos governamentais e autoridades sanitárias, cabe a oferta de informação clara, objetiva e de fácil acesso para toda população, visando à educação de consumidores para o preparo e consumo de alimentos seguros.

\section{REFERÊNCIAS}

[1] Braden CR. Salmonella enterica serotype Enteritidis and eggs: a national epidemic in the United States. Clin Infect Dis. 2006;43(4):512-17.

[2] Brasil. Ministério da Saúde. Secretaria de Vigilância em Saúde - SVS. Análise epidemiológica dos surtos de doenças transmitidas por alimentos no Brasil - 1999-2009 [acesso em 06 nov 2012]. Disponível em: http://portal.saude.gov.br/portal/arquivos/pdf/analise ep surtos dta brasil 2009.pdf
[3] Brasil. Agência Nacional de Vigilância Sanitária. Programa Nacional de Monitoramento da Prevalência e da Resistência Bacteriana em Frango (PREBAF). Relatório do monitoramento da prevalência e do perfil de suscetibilidade aos antimicrobianos em enterococos e salmonelas isolados de carcaças de frango congeladas comercializadas no Brasil [acesso em 06 nov 2012]. Disponível em: http://portal.anvisa.gov.br/wps/wcm/connect/d6fa540047 45870b908fd43fbc4c6735/relatorioprebaf.pdf?MOD=AJPE $\underline{\mathrm{RES}}$

[4] Back A. Por que os programas de controle para Salmonella em aves falham? Aveworld [periódico eletrônico] 2011 [acesso em 22 ago 2012]. Disponível em: http://www.aveworld.com.br

[5] Jay JM (Org.). Microbiologia de Alimentos. Porto Alegre: Artmed; 2005.

[6] Food and Drug Administration. Playing it safe with eggs What you need to know. Food Facts 2011 [cited 2012 Nov 06]. Available from: http://www.fda.gov/downloads/Food/ResourcesForYou/ Consumers/UCM278445.pdf

[7] Franco BGDM, Landgraf M (Org.). Microbiologia dos Alimentos. São Paulo: Atheneu; 2005.

[8] Rodrigue DC, Tauxe RV, Rowe B. International increase in Salmonella enteritidis: a new pandemic? Epidemiol Infect. 1990; 105(1):21-27.

[9] Gama NMSQ. Salmonella spp. em aves de postura comercial [dissertação]. Jaboticabal: Universidade Estadual Paulista; 2001.57 p.

[10] Gantois I, Ducatelle R, Pasmans F, Haesebrouck F, Gast R, Humphrey TJ, et al. Mechanisms of egg contamination by Salmonella Enteritidis. FEMS Microbiol Rev. 2009;33(4):71838.

[11] Guard-Petter J. The chicken, the egg and Salmonella enteritidis. Environ Microbiol. 2001;3(7):421-30.

[12] Ebel E, Schlosser W. Estimating the annual fraction of eggs contaminated with Salmonella enteritidis in the United States. Int J Food Microbiol. 2000;61(1):51-62.

[13] Center for Disease Control and Prevention. Salmonella serotype Enteritidis. General Information. CDC 2010 [cited 2012 Nov 06]. Available from: http://www.cdc.gov/nczved/divisions/dfbmd/diseases/sal monella enteritidis 
[14] Instituto Brasileiro de Geografia e Estatística. Indicadores IBGE: Estatística da Produção Pecuária Setembro de 2012 [acesso em 06 nov 2012]. Disponível em: http://www.ibge.gov.br/home/estatistica/indicadores/agro pecuaria/producaoagropecuaria/abate-leite-couroovos 201202 publ completa.pdf

[15] Oliveira DD, Silva EN. Salmonella em ovos comerciais: ocorrência, condições de armazenamento e desinfecção da casca. Arq Bras Med Vet Zootec. 2000; 52(6):655-661.

[16] Cardoso ALSP, Tessari ENC, Castro AGM, Kanashiro AMI, Gama NMSQ. Presence of Salmonella spp in commercial eggs analysed at the Avian Patology laboratory of Descalvado, SP. Higiene Alimentar. 2002;16(92/93):76-9.

[17] European Food Safety Authority. Scientific Opinion on a quantitative estimation of the public health impact of setting a new target for the reduction of Salmonella in laying hens. EFSA Journal [Portal EFSA]; 8(4) [cited 2012 Nov 21]. Available from: http://www.efsa.europa.eu/en/efsajournal/doc/1546.pdf

[18] Luber P. Cross-contamination versus undercooking of poultry meat or eggs - which risks need to be managed first? Int J Food Microbiol. 2009;134(1-2):21-8.

[19] Gast RK, Beard CW. Production of Salmonella enteritidiscontaminated eggs by experimentally infected hens. Avian Dis. 1990;34(2):438-46.

[20] Pellegrini DCP. Fatores de risco para a contaminação por Salmonella ao longo da cadeia de produção de rações de suínos. In: VI Simpósio Internacional de Suinocultura, 2011, Porto Alegre. Anais... Porto Alegre: VI SINSUI, 2011. p. 3542.

[21] Torres GJ, Piquer FJ, Algarra L, Frutos C, Sobrino OJ. The prevalence of Salmonella enterica in Spanish feed mills and potential feed-related risk factors for contamination. Prev Vet Med. 2011;98(2-3):81-7.

[22] European Food Safety Authority. Report of the task force on zoonoses data collection on the analysis of the baseline study on the prevalence of Salmonella in holdings of laying hen flocks of Gallus gallus. Scientific Report of EFSA [Portal EFSA] 2007 [cited 2012 Nov 21]. Available from: http://www.efsa.europa.eu/en/efsajournal/doc/97r.pdf

[23] Zancan FT, Junior AB, Fernandes SA, Gama NMSQ. Salmonella spp investigation in transport boxes of day-old birds. Braz J Microbiol. 2000;31(3):230-32.

[24] Freitas Neto OC, Mesquita AL, Paiva JB, Zotesso F, Berchieri Júnior A. Control of Salmonella enterica serovar
Enteritidis in laying hens by inactivated Salmonella Enteritidis vaccines. Braz J Microbiol. 2008;39(2):390-96.

[25] International Commission on Microbiological Specifications for Foods. Huevos y ovoproductos. In: ICMSF. Ecología microbiana de los productos alimentarios. Zaragoza: Editorial Acribia; 2001. p. 451-88.

[26] Quinn PJ, Markey BK, Carter ME, Donnelly WJ, Leonard FC (Org.). Microbiologia veterinária e doenças infecciosas. Porto Alegre: Artmed; 2005.

[27] Tranter HS, Board RG. The antimicrobial defence of avian eggs: biological perspective and chemical basis. J Appl Biochem. 1982;4:295-338.

[28] Pinto AT, Silva EN. Ensaios de penetração de Salmonella Enteritidis em ovos de galinha com diferentes qualidades de casca, submetidos ou não à lavagem industrial e a duas temperaturas de armazenagem. Arq Bras Med Vet Zootec. 2009;61(5):1196-1202.

[29] Borges KA, Pinto AT, Silva EN. Efeito da oscilação de temperatura e umidade do ar no comportamento de Salmonella enteritidis em ovos de galinha contaminados. Acta Scientiae Veterinariae. 2009;37(1):25-30.

[30] Humphrey TJ. Contamination of egg shell and contents with Salmonella enteritidis: a review. Int J Food Microbiol. 1994;21(1-2):31-40.

[31] World Health Organization. Risk assessments of Salmonella in eggs and broiler chickens. Microbiological Risk Assessment Series 2. Food and Agriculture Organization of the United Nations [FAO Corporate Document Repository] 2002 [cited 2012 Nov 06]. Available from: http://www.fao.org/docrep/005/Y4392E/Y4392E00.HTM

[32] Gast RK. Bacterial infection of eggs. In: Mead GC (Org.). Food safety control in the poultry industry. Boca Raton: CRC Press; 2005. p. 1-20.

[33] Stadelman WJ. The preservation of Quality in shell eggs. In: Stadelman WJ (Org.). Egg Science and Technology. Connecticut: Westport; 1986. p. 63-73.

[34] Stringhini MLF, Andrade MA, Mesquita AJ, Rocha TM, Rezende PM, Leandro NSM. Características bacteriológicas de ovos lavados e não lavados de granjas de produção comercial. Ci Anim Bras. 2009;10(4):1317-27.

[35] Brasil. Ministério da Agricultura, Pecuária e Abastecimento. Portaria no 1, de 21 de fevereiro de 1990. Aprovar as Normas Gerais de Inspeção de Ovos e Derivados, propostas pela Divisão de Inspeção de Carnes e 
Derivados - DICAR que serão divulgadas através de Ofício Circular da SIPA. Diário Oficial da União, Brasília, 06 mar. 1990. Seção 1, p. 4321.

[36] Barbosa NAA, Sakomura NK, Mendonça MO, Freitas RE, Fernandes JBK. Qualidade de ovos comerciais provenientes de poedeiras comerciais armazenados sob diferentes tempos e condições de ambientes. ARS Veterinária. 2008;24(2):127-33.

[37] Pinto AT. Estudo do comportamento de Salmonella Enteritidis e Escherichia coli na casca, sua penetração no conteúdo interno e alterações na qualidade em ovos de galinha contaminados artificialmente simulando condições usuais de produção comercial [tese]. Campinas: Universidade Estadual de Campinas; 2005. 148 p.

[38] Egg Safety Center [homepage] United Eggs producers [cited 2012 Jun. 14]. Available from: http://www.eggsafety.org

[39] Centro de Vigilância Epidemiológica "Prof. Alexandre Vranjac". Doenças transmitidas por água e alimentos. Salmonella Enteritidis/Salmonelose. Informe Net DTA 2011 [acesso em 12 fev 2012]. Disponível em: ftp://ftp.cve.saude.sp.gov.br/doc tec/hidrica/doc/13SEnte ritidis rev2011.pdf
[40] São Paulo. Centro de Vigilância Sanitária (CVS) da Secretaria de Estado de Saúde de São Paulo. Portaria CVS 18, de 09 de setembro de 2008. Regulamento técnico sobre os parâmetros e critérios para o controle higiênico-sanitário em estabelecimentos de alimentos [acesso em 06 nov 2012]. Disponível em: http://www.cvs.saude.sp.gov.br/zip/E PTCVS-18 090908.pdf

[41] Leal D. Práticas adotadas pelo consumidor na compra e utilização do ovo na alimentação [dissertação]. Piracicaba: Universidade de São Paulo; 2011. 115 p.

[42] Ricke SC, Birkhold SG, Gast RK. Eggs and egg products. In: Downes FP, Ito K. (Org.). Compendium of methods for the microbiological examination of foods. Washington: American Public Health Association; 2001. p. 473-81.

[43] Brasil. Ministério da Saúde. Agência Nacional de Vigilância Sanitária. Resolução RDC no 35, de 17 de junho de 2009. Dispõe sobre a obrigatoriedade de instruções de conservação e consumo na rotulagem de ovos e dá outras providências. Brasília, Diário Oficial da União, Brasília, 18 jun. 2009. Seção 1, p. 47.

[44] Pastore SM, Oliveira WP, Neto ARO, Albino LFT. Ovos processados: produtos e mercado - revisão. Revista Eletrônica Nutritime. 2011;8(2):1499-1508. 